\title{
CHARACTERIZATION OF PLASTIC MATERIALS PRESENT IN MUNICIPAL SOLID WASTE: PRELIMINARY STUDY FOR THEIR MECHANICAL RECYCLING
}

\author{
Mónica Calero ${ }^{1}$, María Ángeles Martín-Lara ${ }^{1}$, Verónica Godoy 1,*, Lucía Quesada ${ }^{1}$, \\ David Martínez ${ }^{2}$, Francisco Peula ${ }^{2}$ and José Manuel Soto ${ }^{2}$ \\ ${ }^{1}$ Department of Chemical Engineering, University of Granada, Avenida Fuentenueva s/n, 18071, Spain \\ 2 INGESIA Ingeniería y Medio Ambiente S.L., C/Parque de las Ciencias, 1, 18014, Granada, Spain
}

Article Info:
Received:
6 June 2018
Revised:
31 August 2018
Accepted:
12 November 2018
Available online:
21 November 2018
Keywords:
Characterization
Dirt
Moisture
Plastic waste
Polymer
Recycling

\section{INTRODUCTION}

Since the Second World War, plastic has been established as one of the essential materials in many areas of everyday life, gaining strength in sectors such as automotive industry, clothing and decoration. From the 1960s to the present day, the demand for plastic products has grown continously. The annual production of plastic has increased twenty-fold in the last fifty years. Among the most commonly used polymers today, different typologies can be cited (Table 1).

One of the major environmental problems is the large amount of plastic waste generated. Both, the production of this material and the incorrect waste management cause several environmental problems. One of those problems is the amount of oil needed to manufacture virgin polymers (up to $6 \%$ of world oil production). Other problems are greenhouse gas emissions during manufacture (more than $1 \%$ of the world total), low recycling rates of waste and dumping of this waste at sea (World Economic Forum et al., 2016). It is estimated that $80 \%$ of the waste present in seas are plastics which come from land (Rojo-Nieto and Montoto, 2017). The problem is that it takes between 100 and 1000 years to degrade plastics, so they suppose a real threat for sea flora and fauna.

In 2015, 322 million tons of plastic were produced worldwide. Europe is the second largest producer behind China. Its production reached 58 million tons that same year. Of this amount, 25.8 million tons were introduced annually into the municipal waste stream, which supposed a $12.4 \%$ of the total municipal solid waste (MSW). A $30.8 \%$ of this plastic waste was deposited in landfills, $39.5 \%$ was utilized for energy recovery and $29.5 \%$ was recycled (PlasticsEurope, 2016). In Spain the situation is even worse than in the EU. In fact, the amount of plastic waste that ends up in landfills is over $50 \%$ in Spain (PlasticsEurope, 2015).

The statistics show that the production of plastics and the plastic waste recycling do not grow in the same way. Increasing the percentages of mechanical recycling would be 
TABLE 1: Most commonly used polymers.

\begin{tabular}{|c|c|c|}
\hline \multirow[t]{2}{*}{$\begin{array}{l}\text { Society of the } \\
\text { Plastics Industry } \\
\text { (SPI) Code }\end{array}$} & Polymer & Applications \\
\hline & Polyethylene terephtalate & Food packaging, carbonated soft drink bottles, water bottles, oil bottles, etc. \\
\hline & High density polyethylene & Bags, detergent bottles, dairy bottles, etc. \\
\hline & Polyvinyl chloride & Pipes, cards, sanitary fittings, etc. \\
\hline & Low density polyethylene & Bags, film, packaging, etc. \\
\hline & Polypropylene & Food packaging, lids, reusable cups, etc. \\
\hline & Polystyrene & Single-use plates and cutlery, yogurts, butter packaging, etc. \\
\hline & Other plastics & Multiple applications \\
\hline
\end{tabular}

a good alternative for reducing the amount of oil used and greenhouse gas emissions, as well as reducing landfill waste.

The aim of this study is the characterization of the various plastic materials existing in mixed municipal solid waste and to assess the need of the washing/drying steps and their potential impact as preliminary preparation steps on the global recycling process line.

\section{MATERIALS AND METHODS}

\subsection{Materials}

The raw material used in this study came from the municipal solid waste collected and treated at the Waste Treatment Plant (Ecocentral) in Granada (Spain), and corresponded to the fraction that had not been collected

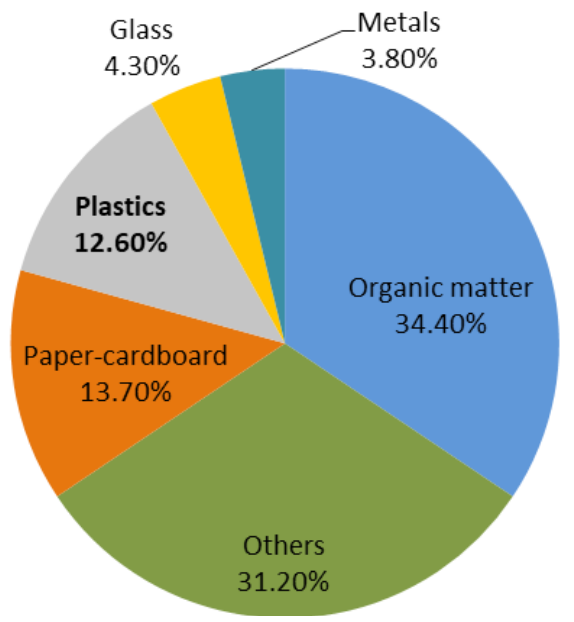

FIGURE 1: Composition of municipal solid waste in Granada (Spain). selectively. Municipal solid waste in Granada is made up of different fractions (Figure 1), among which the organic matter (34.4\%) stands out, while plastic represents $12.6 \%$ of the total. This information comes from periodical characterizations carried out in the plant.

Figure 2 shows the different fractions of the plastic waste.Among them, polyethylene film is the most important, representing approximately $43 \%$ of the total. Plastic waste from all fractions except for rigid high-density-polyethylene, HDPE (mainly bottles) and plastics belonging to the category "Others" were analysed in the laboratory. The category "Others" includes many multilayer plastics, fibres and other polymers which are not the focus of this study.

At the Waste Treatment Plant of Granada, plastic waste is mechanically pre-treated to separate one type from

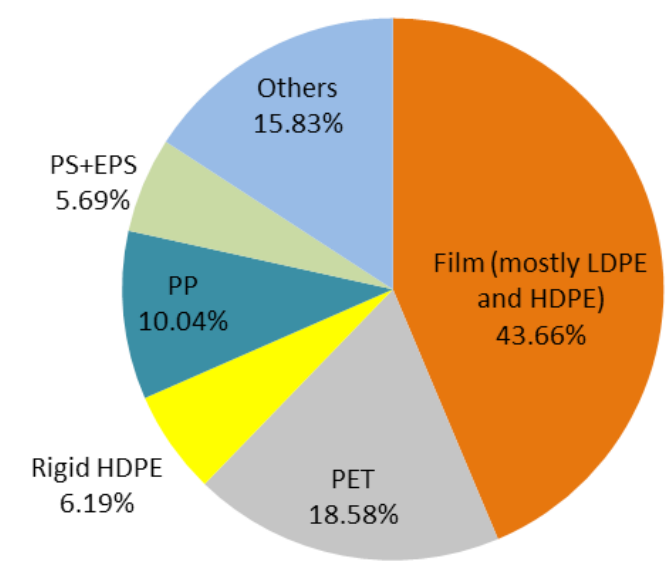

FIGURE 2: Composition of plastic fraction present in municipal solid waste of Granada (Spain). 
another to facilitate the subsequent recycling and baling. The samples analysed in the laboratory came from the bunker corresponding to each type of plastic separated inside the plant (Figure 3). The plastic types analysed are:

- Polyethylene (PE) film (mostly bags and packaging film);

- Polyethylene terephthalate (PET) packaging;

- Polypropylene (PP) packaging;

- Polyestirene (PS) and Expanded Polystyrene (EPS) packaging.

\subsection{Methods}

The first step was the characterization of the plastic waste in the Waste Treatment Plant of Granada (Spain). The plastic waste was then transferred to the laboratory, where a series of analyses were carried out in the following order (Figure 4): 1) measurement of moisture content, 2) grinding, 3) washing and 4) measurement of dirt content. In parallel, the wastewater from the washing of each type of plastic material was analyzed, measuring the dissolved solids content, the total solids content and the chemical oxygen demand (COD).

\subsubsection{Characterization of raw material in the treatment plant and in the laboratory}

The purpose of this characterization was to determine the type of polymer that make up the waste material in order to separate and classify it. Several techniques were used for this purpose. At the municipal waste treatment plant, the plastic waste obtained from the bunkers was analyzed directly by Near Infrared Spectroscopy (NIR) using a portable Panatec Thermo Scientific microPhazir AG, with a wavelength range of $1600-2400 \mathrm{~nm}$. The analysis was performed on the materials while they were in the waste stream, i.e. dirty and wet. This portable NIR spectrometer gives a reference spectrum with a correlation coefficient that indicates the similarity between the two spectra, appart from the measured spectrum.

Only the measurements with coefficients higher than 0.90 were considered. This value indicates that the material of the polymer can be considered to be the same as the reference material. However, this equipment does not provide the numerical values of the absorption peaks. In addition, moisture and dirt present in the material can lead to erroneous absorption peaks, which do not correspond to the polymer.

Thus, in the laboratory, this technique was complemented with Fourier Transform Infrared spectroscopy (FTIR), once the materials were washed and dried, to avoid disturbances caused by moisture and dirt. In addition, this equipment provides the values of the main absorption peaks, which allows comparing them with those in the literature (Bozaci et al., 2012; Rodríguez-Bruceta et al., 2014; Smith, 1999; Vahur et al., 2016; Zieba-Palus, 2017) and confirming the type of polymer that compose the waste.

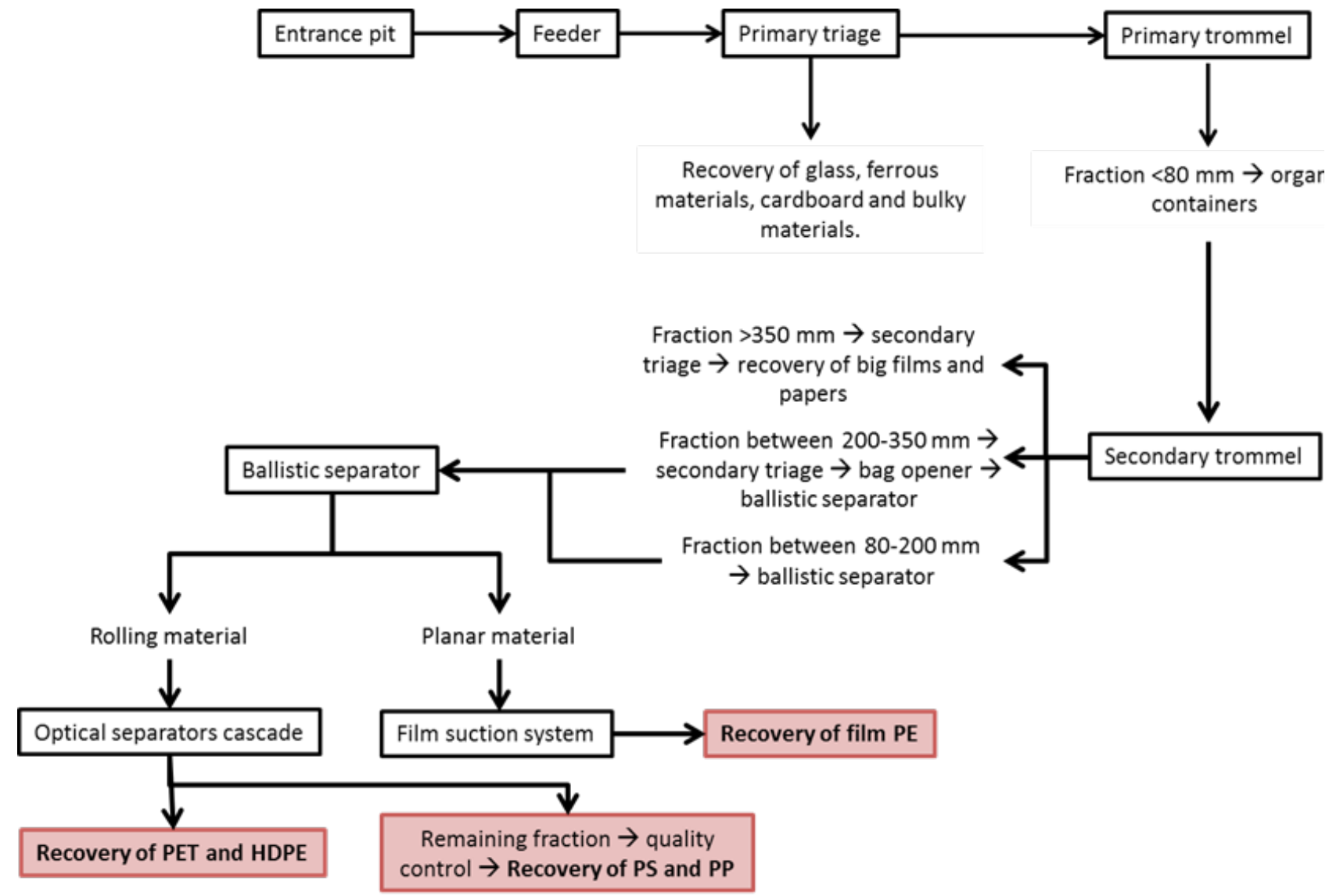

FIGURE 3: Scheme of mechanical pre-treatment carried out inside the Waste Treatment Plant of Granada (Spain). 


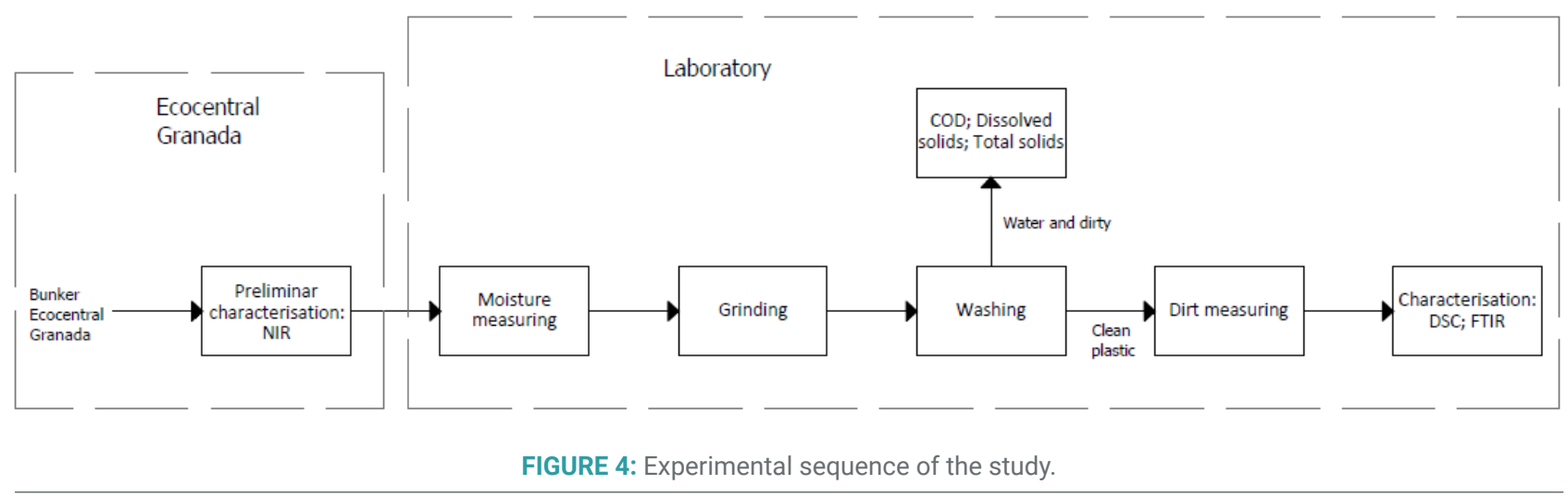

The analysis was performed with a Perkin-Elmer FT-IR Spectrometer model Spectrum 65, which has a wavelength range of $4000-400 \mathrm{~cm}^{-1}$ and a resolution of $2 \mathrm{~cm}^{-1}$.

In the laboratory, tests were also carried out using Differential Scanning Calorimetry (DSC) on the samples in order to obtain the melting points of the different polymers that compose the plastic waste, a technique that is also widely used to complement the previous ones. The analysis was performed on Perkin-Elmer Thermobalance model STA 6000, in accordance with the standard ISO 113573:2018

\subsubsection{Determination of moisture}

Moisture content was determined according to standard UNE-EN ISO 18134-3:2016 using a drying oven at a temperature of $105 \pm 2{ }^{\circ} \mathrm{C}$ during 24 hours.

\subsubsection{Washing process}

Three samples of each of the plastic materials described in section 2.1 were taken and washed. In order to determine the amount of water used in the washing process, several companies expert in the design of washing machines for the mechanical recycling of plastic were consulted. The minimum quantity acceptable for a correct washing is $1 \mathrm{~L}$ per $100 \mathrm{~g}$ of plastic. This quantity was complied for all the polymers except for EPS. A solid:liquid ratio of 1:40 was used for this material, because it is very bulky and it has a very low density, so it takes large amounts of water to submerge it completely and wash it properly. The duration of each wash was 30 minutes. Similar to our methodology, different water quantities were reported for diverse polymers. For example, after performing a cradleto-gate life-cycle inventory (LCI) (EU data) for polymer recycling from post-consumer sources, Hopewell et al., (2009) found that the amount of consumed water was $32 \mathrm{~kL} /$

TABLE 2: Washing conditions.

\begin{tabular}{c|cc} 
Polymer & Temperature & Ratio (plastic:water) \\
\hline PE film & Room; $60^{\circ} \mathrm{C}$ & $1: 10$ \\
\hline PET packaging & Room; $60^{\circ} \mathrm{C}$ & $1: 10$ \\
\hline PP packaging & Room; $60^{\circ} \mathrm{C}$ & $1: 10$ \\
\hline PS packaging & Room & $1: 10$ \\
\hline EPS packaging & Room & $1: 40$ \\
\hline
\end{tabular}

tonne for high-density polyethylene (HDPE), $43 \mathrm{~kL} /$ tonne for polypropylene (PP), $66 \mathrm{~kL} /$ tonne for (PET) and $140 \mathrm{~kL}$ / tonne for polystyrene (PS).

Washing was carried out using water from the urban network, which has a total dissolved solids (TSD) of 74.4 $\mathrm{mg} / \mathrm{l}$.

With regard to temperature, the plastic was washed at room temperature $\left(23-25^{\circ} \mathrm{C}\right)$ and using hot water $\left(60^{\circ} \mathrm{C}\right)$ following the recommendations given by other authors in the literature (Al-Sabagh et al.,, 2016; Awaja and Pavel, 2005; Kratofil et al., 2014; Luijsterburg, 2014; Rodríguez-Bruceta et al., 2014) (Table 2).

\subsubsection{Determination of dissolved solids, total solids and} $C O D$ in wastewater

After the washing, the wastewater was analyzed and the following parameters were measured: dissolved solids, total solids and chemical oxygen demand (COD). These parameters were measured because they are the ones that determine the quality of the wastewater before it is discharged into the network. The methodology used to determine each of these parameters is described below:

- Dissolved solids: They were determined gravimetrically by vacuum filtration, according to UNE 77031:2015, using a Filter-Lab 1240 filter, with a pore size of 14-18 $\mu \mathrm{m}$. The filtered water was then allowed to dry in a $105^{\circ} \mathrm{C}$ oven and the remaining solid residue was weighed. The result is expressed in $\mathrm{g} / \mathrm{L}$.

- Total solids: They were determined by the difference in weight between dirty plastic and clean plastic. The result is expressed in $\mathrm{g} / \mathrm{L}$.

- COD: This parameter has been determined in accordance with ISO 6060:1989, using the dichromate method. The chemical oxidizer was added to the wastewater and boiled. It remained in this state for a time, after which it was reduced through a reducing agent. Finally, it was evaluated in order to measure the amount of chemical oxidant consumed, expressed in $\mathrm{mg} / \mathrm{L}$ of equivalent oxygen.

\subsubsection{Determination of dirt loss}

Dirt loss was determined considering the weight loss of the plastic after the washing process. This parameter corresponds to the total solids parameter, as both measure the same solid fraction, but expressed in different units. 
This is why the same values are presented in Table 3 for dirt loss as in Tables 4 and 5 for total solids.

The loss of dirt is expressed in percentage.

\section{RESULTS AND DISCUSSION}

\subsection{Identification of polymers existing in raw mate- rial}

The infrared spectra obtained by the NIR technique in the plant revealed that the majority of plastic materials analysed were composed of PE, PET, PP, PS, EPS and PA. This result coincides with the characterization presented in Figure 2, so it can be stated that the majority of plastic wastes contained in MSW are composed of PE, PET, PP, PS, EPS and PA (Figure 5).

However, due to the heterogeneity and characteristics of the sample in the field analysis with the NIR equipment, in some cases FTIR technique in the laboratory was performed as well (Figure 6). The spectra obtained were compared with spectra from the literature of pure polymers (Bozaci et al., 2012; Rodríguez-Bruceta et al., 2014; Smith, 1999; Vahur et al., 2016; Zieba-Palus, 2017). It was found that the absorption peaks coincided with those described for PE, PET, PP, PS and PA by these authors. In the case of $P E$, in the characterization with FTIR, it was possible to differentiate between high density polyethylene (HDPE) and low density polyethylene (LDPE), since there is at least one different absorption peak between both, according to other authors (Kochetov et al., 2017; Rodríguez-Bruceta et al., 2014; Smith, 1999).

Another method used to verify the type of polymer, as described in section 2.2.1, was the DSC. This method is considered as the most decisive in polymer characterization, since it provides the melting temperature. All the polymers analyzed gave consistent results except PA. In the characterization phase, this material was detected only in multilayer products, containing PET or PE in addition to PA, and the layers could not be separated. This resulted in numerous overlapping and difficulties to identify fusion peaks in the DSC. For that reason, the DSC of these materials has not been included in the results.

Figure 6 shows the results obtained in the laboratory. In the case of PET, the melting temperatures reported by other authors (Awaja and Pavel, 2005; EAG Laboratories, 2018) were between $250-265^{\circ} \mathrm{C}$, although slightly lower temperatures can be obtained,which is consistent with the results presented in this paper. For $\mathrm{PP}$, the melting temperature is usually higher than $160^{\circ} \mathrm{C}$ (Hindle, 2018; Mofokeng et al., 2011), coinciding with the DSC shown in Figure

TABLE 3: Moisture and dirt content at different temperatures for each polymer.

\begin{tabular}{c|ccccccc} 
& PE & PET & PP & PS & EPS \\
\hline $\begin{array}{c}\text { Moisture } \\
(\%)\end{array}$ & 11.78 & 8.90 & 1.58 & 20.98 & 16.10 \\
\hdashline $\begin{array}{c}\text { Dirt (\%) at room } \\
\text { temperature }\end{array}$ & 13.79 & 8.50 & 2.65 & 10.20 & 7.91 \\
\hdashline $\begin{array}{c}\text { Dirt (\%) in hot } \\
\text { water }\end{array}$ & 13.17 & 6.45 & 1.53 & -- & - \\
\hline
\end{tabular}

6. In the case of PS and EPS, the temperature obtained in the DSC is the glass transition temperature since they do not have melting temperature because they are amorphous polymers (Oliveira et al., 2013; Parres-García, 2005). This value is usually around $100^{\circ} \mathrm{C}$, which is in accordance to the value obtained in the present investigation.

It should be noted that, within the PE, the DSC technique could be used to distinguish between HDPE and LDPE whose melting temperatures are different. HDPE may have melting temperatures between $120-130^{\circ} \mathrm{C}$ (Chianelli et al., 2013), but in most cases the values are closer to $130^{\circ} \mathrm{C}$ or even higher, such as those obtained by some authors (Araújo et al., 2008; Shnawa et al., 2015) and in the DSCs presented in this article. On the other hand, the melting temperature of low-density polyethylene is usually between $115-125^{\circ} \mathrm{C}$ (Batra, 2014), but it can fluctuate slightly above or below these values since other authors have obtained melting temperatures of $113^{\circ} \mathrm{C}$ or $127^{\circ} \mathrm{C}$ (Ashraf, 2014; Poley et al., 2004). These values are also in accordance with those shown in Figure 6 for the LDPE.

All the results obtained by these three techniques allowed to separate and quantify precisely the composition of the fraction of plastic material contained in the MSW, as well as to confirm the results of Figure 2.

\subsection{Moisture and dirt content of plastic materials}

Table 3 shows the data related to moisture and dirt obtained for all types of plastic materials separated from mixed municipal solid waste of the province of Granada (Spain). The samples with the highest moisture content were PS, EPS and PE film. Other authors such as Carranza et al.,, 2010 obtained moisture values of $10-20 \%$ for PE film waste from greenhouses.

With regard to the dirt present in plastics, it was found that most of it was made up of organic matter (soil, plant debris, etc.), paint and chemical residues, as well as labels and glue residues. Organic matter was more abundant in PE waste, paint and chemicals were present in PP waste, while labels and glue residues were more abundant in PET, PS and EPS. The labels were removed after the material had dried, as they were easily detached. After removal they were weighed. They represent between $10-14 \%$ of the plastic material and they are therefore an important parameter to take into account for mechanical recycling. Organic matter and paint residues were removed during washing.

The waste that contains the most dirt is PE film, followed by PS. PP had very low dirt loss values. This causes the viability of mechanical recycling and the quality of the final product can vary from one material to another. The

TABLE 4: Characteristics of washing water at room temperature.

\begin{tabular}{|c|c|c|c|c|c|}
\hline & PE & PET & PP & PS & EPS \\
\hline $\begin{array}{c}\text { Total dissolved } \\
\text { solids }(\mathrm{g} / \mathrm{l})\end{array}$ & 5.64 & 3.52 & 0.59 & 5.71 & 1.00 \\
\hline $\begin{array}{l}\text { Total solids } \\
(\mathrm{g} / \mathrm{l})\end{array}$ & 13.79 & 8.50 & 2.65 & 10.20 & 7.91 \\
\hline $\operatorname{COD}\left(\mathrm{mgO}_{2} / \mathrm{l}\right)$ & 1920 & 851.57 & 208.67 & 526 & 340.25 \\
\hline
\end{tabular}


TABLE 5: Characteristics of hot washing water.

\begin{tabular}{|c|c|c|c|c|c|}
\hline & PE & PET & PP & PS & EPS \\
\hline $\begin{array}{l}\text { Total dissolved } \\
\text { solids }(\mathrm{g} / \mathrm{l})\end{array}$ & 5.68 & 2.04 & 0.40 & - & - \\
\hline $\begin{array}{l}\text { Total solids } \\
(\mathrm{g} / \mathrm{l})\end{array}$ & 13.17 & 6.45 & 1.53 & - & - \\
\hline $\operatorname{COD}\left(\mathrm{mgO}_{2} / \mathrm{l}\right)$ & 1733 & 510.29 & 210 & - & - \\
\hline
\end{tabular}

loss in weight of dirt is not necessarily determined by the temperature of the washing.

Washing with hot water did not imply a greater loss of dirt in terms of weight. In fact, the opposite effect was observed (Table 3). It was found no significant difference in the loss of dirt from the material when washing PE, PET and PP at room temperature or in hot water. Therefore, PS and EPS were washed only at room temperature, in order to save water and electricity. However, the use of hot water made it possible to better remove paint and glue residues and improved the loss of fat, giving the washed material a brighter appearance.

Differences in overall weight loss were significant between different types of waste: While PP had an overall weight loss of approximately $4 \%$, the weight loss measured for PS was $30 \%$ of its weight after drying and cleaning by water. These results are of special interest from the point of view of the recycling process of these materials.

\subsection{Determination of dissolved solids, total solids and COD on washing water}

Tables 4 and 5 show the characteristics of the washing waters at room temperature and hot temperature. Dissolved solids, total solids and COD were determined for the different kinds of water. Washing in hot water did not imply a greater presence of dissolved solids in the water.

The wastewater will need to be pre-treated depending on the legislation concerning discharge to the sewerage networks of each city or country.

In the case of Granada, the Spanish province where this study was carried out, both the values of dissolved and total solids and the COD value comply with the limits established by the Municipal Ordinance regulating discharges to the sewage network of the Granada City Council, except in the case of polyethylene film. The COD values obtained for this material exceed the limits $\left(1400 \mathrm{mgO}_{2} / \mathrm{L}\right)$, so its wastewater will need to be pre-treated prior to discharge. This pre-treatment would include several steps of decantation and aerobic degradation designed in order to achieve the discharging limits. The need of these steps will increase the initial cost of the recycling plant. In those cases, where a separate discharging network for industrial waste stream exists, purifying equipment will not be necessary.

\section{CONCLUSIONS}

The study carried out in this work is the first part of an investigation for the mechanical recycling of different types of plastic materials in order to promote this type of
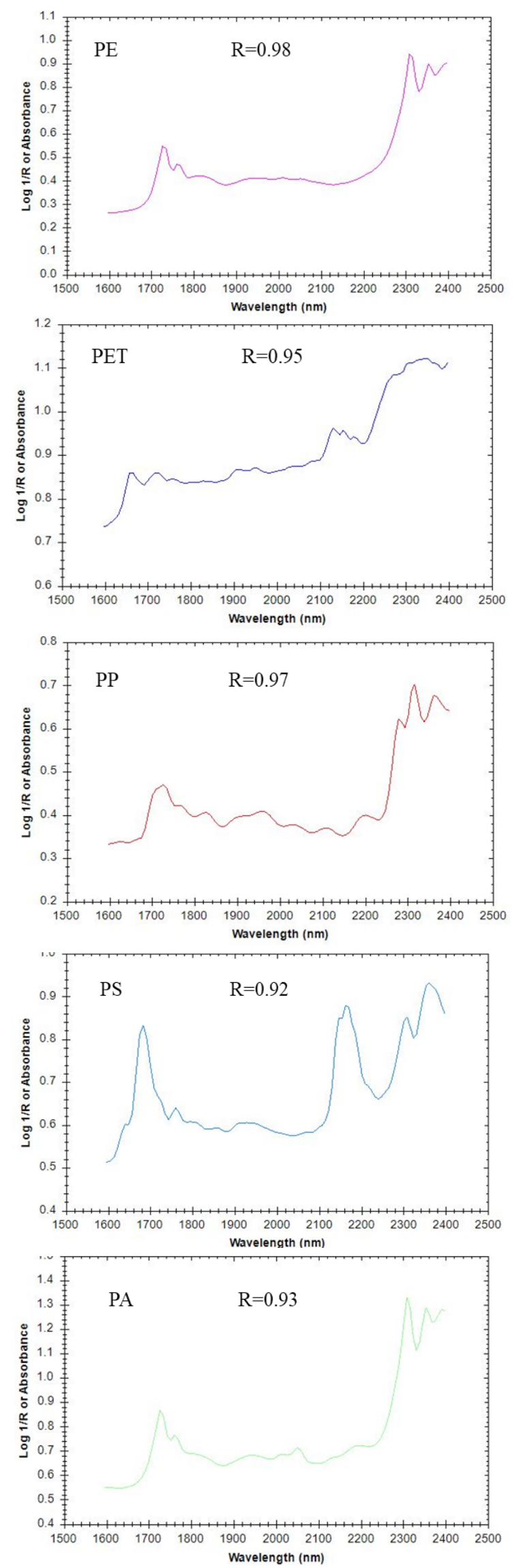

FIGURE 5: NIR spectra of the different plastic waste identified in MSW of Granada (Spain). 
A) FTIR HDPE

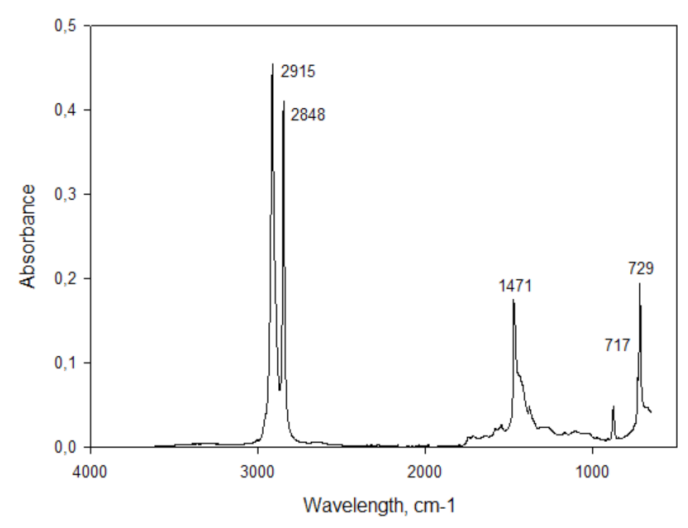

C) FTIR PET

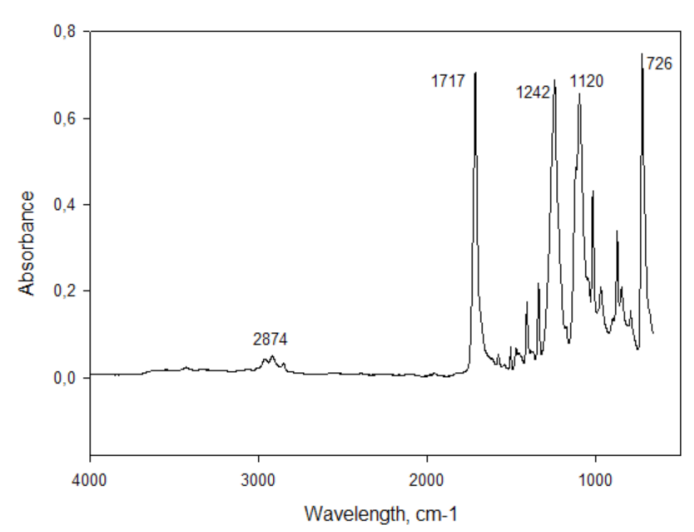

E) FTIR PS/EPS

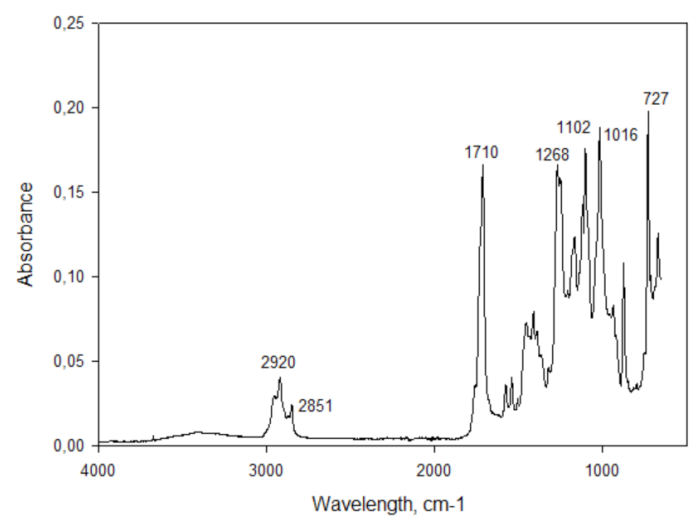

G) DSC HDPE

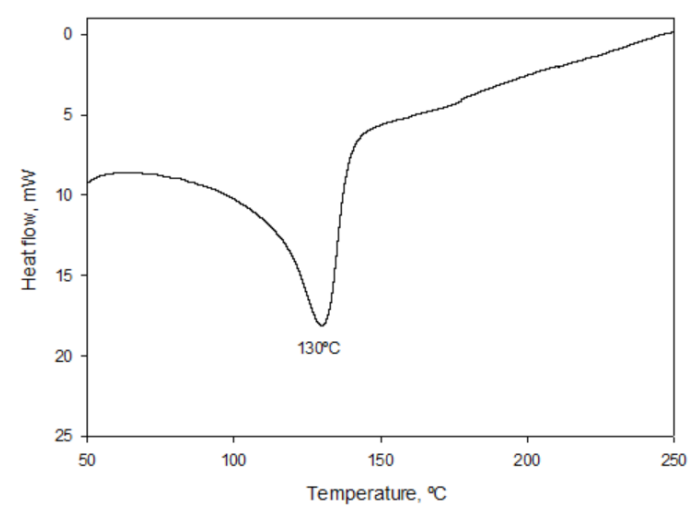

B) FTIR LDPE

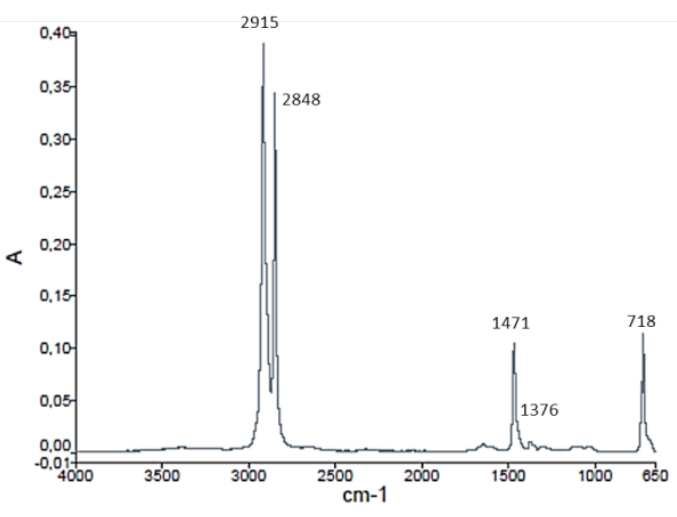

D) FTIR PP

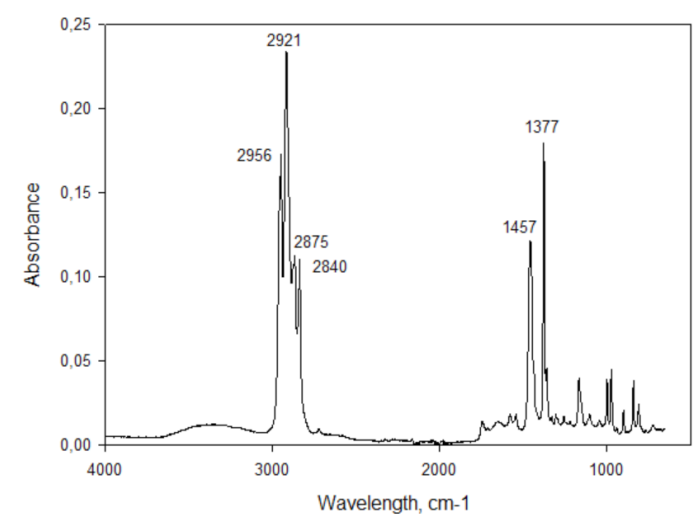

F) FTIR PA

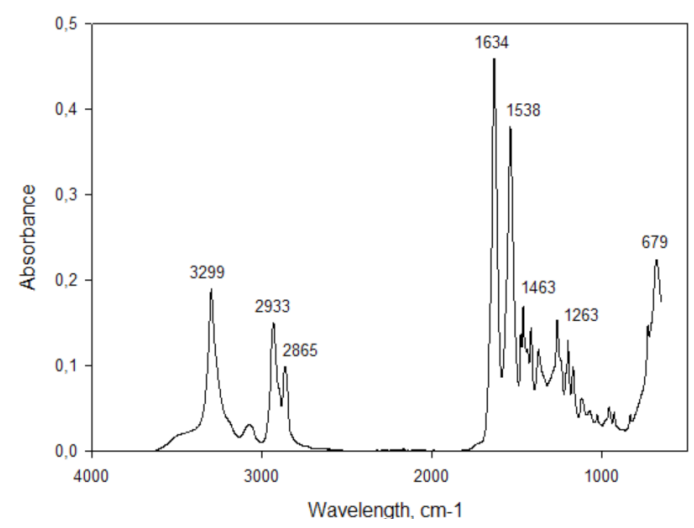

H) DSC LDPE

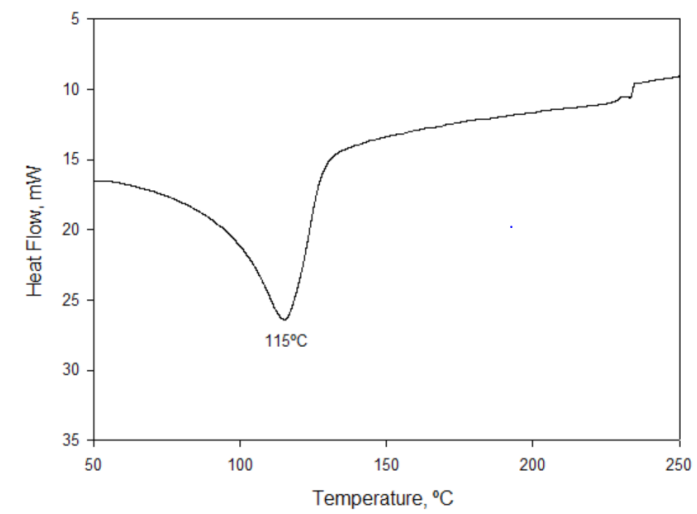


I) DSC PET

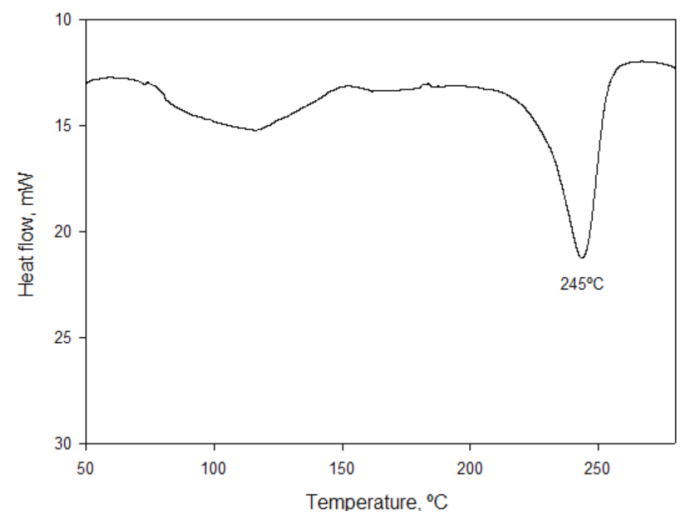

K) DCS PS/EPS

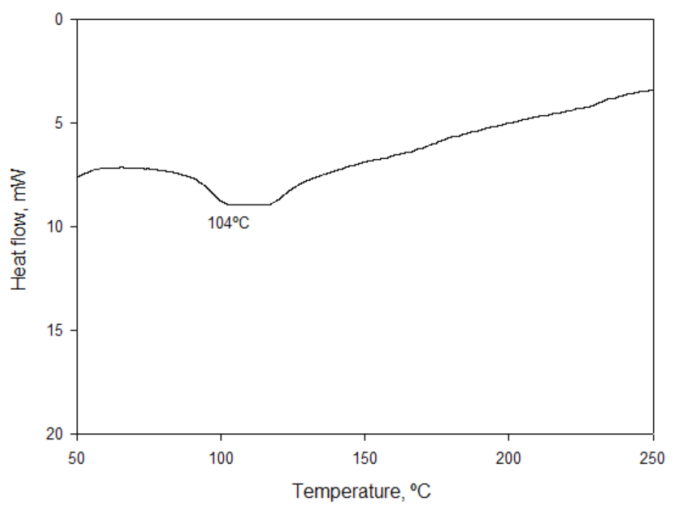

J) DSC PP

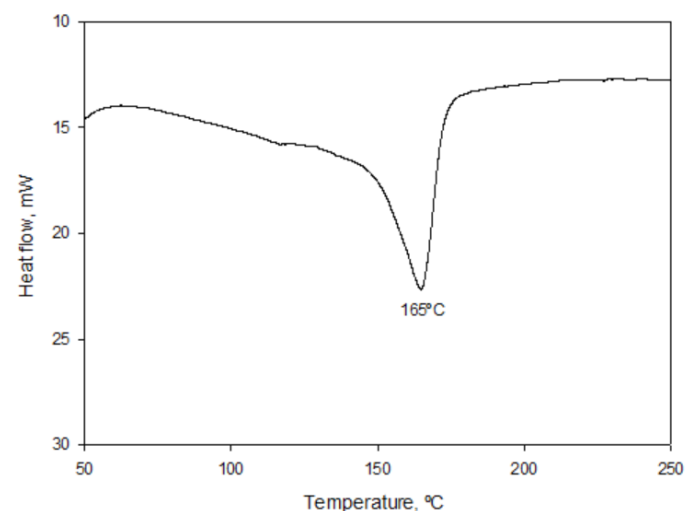

FIGURE 6: A-E) FTIR spectra obtained in laboratory of plastic waste present in MSW of Granada (Spain); F-I) DSC obtained in laboratory of plastic waste present in MSW of Granada (Spain).

recycling among plastic waste from mixed municipal solid waste. Mechanical recycling is a good alternative today to reduce the amount of waste that ends up in landfills in order to reduce the amount of oil needed to make virgin polymers and to contribute to reducing greenhouse gas emissions.

The characterization of the raw material carried out with various Infrared Spectroscopy and DSC techniques showed that the plastic fraction of the MSW from Granada (Spain) was composed mainly of PE, PET, PP, PS and PA.

With regard to the data found during the washing process, moisture and dirt in the waste were key factors in mechanical recycling, as it can account for up to $30 \%$ of its weight. This affects the performance of the process depending on the waste in each case. PS is the material that contains the most moisture and PE the most dirt. PP is a material with less moisture and dirt in general and for that reason it loses little weight during the process. It is important to take these parameters into account because depending on the final treatment that the recycled product will have (injection, blowing, extrusion, etc.), the previous stages of washing and drying may be decisive. It was also concluded that temperature was a non-significant factor in the amount of dirt loss in terms of weight, but it did allow better removal of paint, fat and glue. From the point of view of feasibility, materials such as polyethylene film can be washed at room temperature to reduce energy costs, since their main source of dirt is organic matter (plant debris and soil). Finally, it should be noted that, in most cases, the waste water from the plastic washing process would not require further treatment for discharge in Granada (Spain). However, it would be necessary in the case of the PE.

\section{ACKNOWLEDGEMENTS}

The authors are grateful to the companies Ingesia S.L. and STUC S.L. for their contribution to this research.

\section{REFERENCES}

AENOR. UNE 77031:2015. Calidad del agua. Determinación de los sólidos disueltos.

AENOR. UNE-EN 14346:2007. Characterization Of Waste-Calculation Of Dry Matter By Determination Of Dry Residue Or Water Content.

Al-Sabagh, A., Yehia, F., Eshaq, G., Rabie, A. and ElMetwally, A. (2016). Greener routes for recycling of polyethylene terephthalate. Egyptian Journal of Petroleum, 25, 53-64.

Araújo, J.R., Waldman, W.R., De Paoli, M.A. (2008). Thermal properties of high density polyethylene composites with natural fibres: coupling agent effect. Polymer Degradation and Stability, 93, 1770-1775.

Ashraf, A. (2015). Thermal analysis of polymer by DSC technique. Center for Advanced Materials, Qatar University.

Awaja, F. and Pavel, D. (2005). Recycling of PET. European Polymer Journal, 41, 1453-1477.

Ayuntamiento de Granada (2010). Ordenanza Municipal Reguladora de los Vertidos a la Red de Alcantarillado del Ayuntamiento de Granada. Boletín Oficial Provincial 137, 58-77. 
Bozaci, E., Arik, B., Demir, A. and Özdogan, E. (2012). Potential use of new methods for identification of hollow polyester fibres. Tekstil ve Konfeksiyon 4, 317-323.

Carranza, N. (2010). Diseño del proceso de lavado de residuos plásticos provenientes de invernadero. Escuela Politécnica Nacional, Quito, Ecuador.

Chianelli-Junior, R., Reis, J.M.L., Cardoso, J.L., Castro, P.F. (2013) Mechanical characterization of sisal fiber-reinforced recycled HDPE composites. Materials Research, 16 (6), 1393-1397.

EAG Laboratories (2018). Using differential scanning calorimetry to characterize polymers. United States: Azo Materials. Recovered from https://www.azom.com/article.aspx?ArticlelD=15458 on 4 June 2018.

Hindle, C. (2018). Polypropylene (PP). Edinburgh Napier University. Recovered from http://www.bpf.co.uk/plastipedia/polymers/ PP.aspx on 27 July 2018.

Hopewell, J., Dvorak, R., Kosior, E. (2009). Plastics recycling: challenges and opportunities. Philosophical Transactions of The Royal Society B, 364, 2115-2126.

International Organization for Standardization. ISO 11357-3:2018. Plastics. Differential scanning calorimetry (DSC). Part 3: Determination of temperature and enthalpy of melting and crystallization.

International Organization for Standardization. ISO 6060:1989. Water Quality. Determination of the chemical oxygen demand.

Kratofil, L., Hrnjak, Z. and Katančic, Z. (2014). Plastics and priority during the recycling. In: N. Gaurina-Medjimurec (ed.), Handbook of research on advancements in environmental engineering (pp. 257-284).

Luijsterburg, B. (2015). Mechanical recycling of plastic packaging waste. PhD Thesis. Technische Universiteit Eindhoven, The Netherlands.

Mofokeng, J., Luyt, A., Tábi, T. and Kovács, J. (2011). Comparison of injection moulded, natural fibre-reinforced composites with PP and PLA as matrices. Journal of Thermoplastic Composite Material, 25(8), 927-948.

Oliveira, R., Ferreira, C., Peixoto, L., Bianchi, O., Silva, P., Demori, R., Silva, R. and Veronese, V. (2013). Mistura polipropileno/poliestireno: um exemplo da relação processamento-estrutura-propriedade no ensino de polímeros. Polímeros, 23(1), 91-96.
Parres-García, F. (2005). Investigación de las variables limitantes en la recuperación de residuos de poliestireno procedentes del sector envase. Tesis Doctoral. Universidad Politécnica de Valencia, Valencia, España.

PlasticsEurope (2015). Business Data and Charts 2015- Spain. PlasticsEurope. Recovered from https://www.plasticseurope.org/en/ resources/publications on 10 April 2018.

PlasticsEurope (2016). An analysis of European plastics production, demand and waste data. Plastics - the Facts 2016. PlasticsEurope. Recovered from https://www.plasticseurope.org/en/resources/ publications on 10 April 2018.

Poley, L.H., Siqueira, A., Da Silva, M., Vargas, H. (2004). Phototermal characterization of low density polyethylene food packages. Polímeros: Ciência e Tecnologia, 14 (1), 8-12.

Rodríguez-Bruceta, P.A., Pérez-Rodríguez, A. and Velázquez-Infante J. (2014). Propuesta de un procedimiento para el reciclado del polietileno de alta densidad. Revista Cubana de Química, 27, 32-54.

Rojo-Nieto, E. and Montoto, T. (2017). Basuras marinas, plásticos y microplásticos: orígenes, impactos y consecuencias de una amenaza global. Madrid, España: Ecologistas en Acción.

Shnawa, H.A., Khaleel, M.I., Muhamed, F.J. (2015). Oxidation of HDPE in the presence of PVC grafted with natural polyphenols (tannins) as antioxidant. Open Journal of Polymer Chemistry, 5, 9-16.

Smith, B.C. (1999). Infrared spectral interpretation. A systematic approach. United States: CRC Press.

Vahur, S., Teearu, A., Peets, P., Joosu, L. and Leito, I. (2016). ATR-FTIR spectral collection of conservation materials in the extended region of $4000-80 \mathrm{~cm}-1$. Analytical and Bioanalytical Chemistry, 408, 3373-3379.

World Economic Forum, Ellen MacArthur Foundation and McKinsey \& Company (2016). The New Plastics Economy - Rethinking the future of plastics. Recovered from http://www.ellenmacarthurfoundation.org/publications on 13 January 2018.

Zieba-Palus, J. (2017). The usefulness of infrared spectroscopy in examinations of adhesive tapes for forensic purposes. Forensic Science and Criminology. 